\title{
Re-Framing Environmental Social Science Research for Sustainable Water Management in a Changing Climate
}

\author{
Rebecca Pearce $\cdot$ Suraje Dessai $\cdot$ Stewart Barr
}

Received: 23 March 2012 / Accepted: 17 October 2012 /

Published online: 27 October 2012

(C) Springer Science+Business Media Dordrecht 2012

\begin{abstract}
This paper considers aspects of environmental social science research in the UK and explores an obvious bias towards the development of instruments to manage demand as an adaptation to climate change, and consequently the predominance of interest in the customer from a demand-side perspective. In the case of water, this has resulted in an inappropriate mixing of individualist research methods designed to measure public perceptions of risk and water-based practices, with mass consumption data that cannot be specifically linked to the individual. This mixing has a tendency to reinforce a long-standing blame culture that drives interest in the development of behaviour change initiatives while the relatively unchallenged hydraulic mission to provide safe drinking water and sanitation progresses. With this in mind this paper reviews examples of water use research from California, Australia, and the UK and highlights the more effective routes to understanding water customers and developing behaviour change initiatives that utilise stages of change models and grounded techniques incorporating qualitative and quantitative data from individual sources. A secondary aim is to argue for re-framing the relations between various actors in a changing climate to allow the development of new policy approaches, learning, and openness, from industry, regulators, and customers, based on new theories from the field.
\end{abstract}

Keywords Behaviour change $\cdot$ Water customer $\cdot$ Environmental social science research $\cdot$ Water management $\cdot$ Climate change

\section{Introduction}

The anticipated effects of climate change combined with lifestyle change and increasing population density brings forth the prospect of water scarcity and damage to ecosystems

R. Pearce $(\bowtie) \cdot$ S. Barr

Geography, College of Life and Environmental Sciences, University of Exeter, Exeter EX4 4RJ, UK

e-mail: rp292@exeter.ac.uk

\section{S. Dessai}

Sustainability Research Institute and ESRC Centre for Climate Change Economics and Policy,

School of Earth and Environment, University of Leeds, Leeds LS2 9JT, UK 
from over abstraction and pollution (European Commission 2007; Environment Agency 2009). Under a medium emissions scenario the Department for Environment, Food and Rural Affairs (Defra), in their UK Climate Change Risk Assessment (Defra 2012a) anticipates with medium confidence, up to a $30 \%$ decrease in deployable output of water by 2050 , which will affect between 27 and 59 million people. This reduction is most likely to impact areas of southern England with large populations (Rance et al. 2012). Charlton and Arnell (2011) point out that as a consequence, "there is considerable potential for substantial and potentially dangerous supply failures as a result of climate change by 2035, in the absence of adaptation." (Charlton and Arnell 2011, p243). The Water Act 2003 handed additional powers to the Environment Agency to regulate abstraction to achieve sustainable water resources management. Prior to this privatization of water services in England and Wales in 1989 had introduced the Agency's forerunner, the National Rivers Authority, which took responsibility for the aquatic environment, and the Drinking Water Inspectorate, which was created to reassure customers regarding the quality of drinking water. The 1991 Water Industry Act provided both economic regulation and good customer relations through the formation of an economic regulator, the Water Services Regulation Authority (Ofwat) and a Non Departmental Government Body, the Consumer Council for Water. Working under the close scrutiny of these four organizations, the task for water managers in this uniquely privatized industry in England and Wales therefore, is one of securing supplies of a finite, though infinitely recyclable natural resource, to meet customers' demands, often within a highly regulated market where price, quality, and environmental stewardship are technically equally important. For example, adhering to the Water Framework Directive, water companies are required to ensure "sustainable water resources that benefit people and wildlife" (Environment Agency 2003) through careful management of water bodies and a combination of metering, pricing, infrastructural development, and water-saving initiatives (Ofwat 2010). However, the emphasis placed by the water industry on meeting demands of customers often overshadows compliance with environmental legislation. The water white paper published in December 2011, describes the situation well in asking these questions:

"How do we protect the environment and take less water from our rivers, while meeting the demands of a growing population? How do we encourage innovation and dynamism in the water sector while ensuring it remains a low-risk choice for investors? How do we incentivise less wasteful use of water while keeping water affordable for everyone?" (Defra 2011 p8).

The expectation of a sustainable water industry therefore has still not been met and the dichotomous nature of these questions highlights the competing aspects of sustainable water management.

Since the 1989 Water Act paved the way for privatisation of the water and sewerage sectors in the UK (House of Lords Science and Technology Committee 2006), water has been viewed both as a natural resource and a commodity, their treatment and management regulated by separate agencies. Commodification and regulation have framed water from two distinct perspectives or sides: demand and supply. As a consequence water sector research in the UK is generally divided between that which focuses on engineering and technical solutions to problems of supply and pollution, and separate behavioural analysis of customer demand. The former possibly harking back to a great "hydraulic mission" (Turton and Meissner 2002, p2) of government, to use technology and engineering to bring water and sanitation to populated areas, the latter attending to the framing of climate change as a customer issue and the dominance of the attitude-behaviour-choice (ABC) paradigm. According to Shove (2010) this paradigm has for a period of 20 years or more resulted in 
"patchy" geography and sociology dominated by psychology and economics in commissioned research, where: "The popularity of the ABC framework is an indication of the extent to which responsibility for responding to climate change is thought to lie with individuals whose behaviour choices will make the difference." (Shove 2010, p1247). This split between water engineering and social engineering is reinforced in Sofoulis' opinion by a conventional division between "non-human and material sciences from sciences of the human" (Sofoulis 2005, p 446), although traces of the hydraulic mission remain evident in technological development. Recently, the Technology Strategy Board (March 2012) invited applicants to compete for funding for "a product, process, service, or business model that has the potential to save or make available for use 1,000 million litres a day (Ml/d) of water, within a defined global market, from the blue water cycle." This highlights the potential opportunity for the technology sector to profit from innovations designed to tackle the threat of water scarcity. However, Gleick (1998) points to the twin constraints of economy and environment that make it increasingly difficult to build new water supply systems in developed nations which have resulted in a "a growing interest in exploring options on the other side of the equation-the demand side." (Gleick 1998, p571). It is therefore the increasingly noticeable bias towards anthropocentric demand-side aspects of water management research that this paper is concerned with. In writing about this bias the authors will go some way to explain how specific framings around water management issues maintain the apparent dichotomy. As a result this paper calls for new approaches to research that allow new theories to emerge from the field, rather than repeated verification studies that rely on popular methods and paradigms, as these are stifling progress in an area of research that should be making an important contribution to sustainable development goals.

This review is a part contribution to an Economic and Social Research Council funded $\mathrm{PhD}$ studentship, which looks at the impact of drought and climate change on water customer behaviour. Although it primarily explores the blame culture that exists between water managers, policy-makers and water customers, the core purpose of writing this paper is to identify problems in environmental social science research that have resulted in a lack of forward movement in this area and a reinforcement of the blame culture to the benefit of water companies and the detriment of the environment. In section two, the conflicting messages of security and scarcity and accompanying industry and policy-based blame cultures are analysed from both customer and user perspectives. The role of environmental social science researchers in sustaining this position is developed in the context of individualist and systemic paradigms (Spaargaren 2011). Section three introduces the demandsupply debate in the context of sustainable development and how this has been utilised to emphasise the attitude-action gap and the importance of interventions to effect behaviour change that are based on attitudinal typologies. In section four, the application of research techniques and models that allow water use to be viewed through alternative 'frames' are discussed. The limited choice of theoretical positions, perspectives and models chosen by environmental social researchers in the context of encouraging behaviour change is critiqued and examples of the framing of recent customer research in the UK are used to illustrate the points made. Section five looks at the popular development of water user typologies and segmentation models and discusses whether these are inappropriate for use in other areas of environmental research. The nature of frames that block the emergence of alternative views of behaviours is contrasted against research methods that follow stages of change and are not therefore rooted to a pre-set perspective. Section six argues for a more open and holistic approach to environmental social science research for water management, that is less directed by concerns over climate change, sustainability, lifestyle, and scarcity, that are used to frame such research. Section seven highlights the limited scope of prevalent social science 
methods to investigate and analyse a broad spectrum of social, technical, and infrastructural aspects of water demand and highlights the more satisfactory results obtained through the use of grounded methods. A call for theories that are grounded in empirical data from water customer studies is furthered through the introduction of Classic Grounded Theory as a workable methodology for research in this area. The paper concludes with optimism for the future of a more flexibly framed format to environmental social science research for water management that is approached with an open mind.

\section{Aspects of Demand-Side Water Research: Sustaining a Blame Culture}

The driver of demand-side water research is an as yet unknown future climate and the desire to know whether the public will continue to use water as they do now, or if they can be encouraged to demand less, should frequent drought and an increasing population impact on the quantity and quality of natural resources available. In the UK, increases in the numbers of single person households, and appliances that use water are both cited as key factors driving demand (House of Lords Science and Technology Committee 2006). For those involved in the provision of potable water and sewerage services in England and Wales, to be able to predict future trends and anticipate future problems is particularly desirable as customers have become accustomed to protected entitlement (Sofoulis 2011) to the water they pay for. The ability to model future climate and to place alongside observations from past and present consumer behaviour creates a new imagined future of scarcity and escalating costs. However, Dessai and Hulme (2004) have questioned the usefulness of using climate change probabilities as a tool to positively manipulate future human behaviour patterns, drawing the conclusion that human reflexive uncertainty ensures we cannot predict how things will turn out. Receipt of this type of information does not guarantee appropriate action by the individual.

Varying levels of uncertainty regarding possible outcomes impact on water management and decision-making. As Dessai and Hulme (2007) have shown, for the east of England, the models and techniques used to assess the robustness of water resource management plans can reinforce the expectation of secure supplies. But at the same time, these models cannot predict changes in customer demand in future years that are likely to emerge from individual water use habits that are formed and re-formed by cultural, technical and value changes. Medd and Shove (2007, p3) have argued that work already completed in analysing the water industry's existing infrastructure and standard approaches to water management, coupled with knowledge of consumer preferences, and cultural influences, reveals that we are experiencing a "crisis in the making" and that "Much of the future is already with us." As such, the prophecy of a water-scarce future driven by myriad consumption practice scenarios that are constantly unfolding in the present, coupled with out-of-date infrastructure and management based on our past, is already upon us. As Bakker (2003, p28) reminds us, this is not an absolute scarcity of water but a socially produced scarcity, without which market-based solutions to water management and provision will not work (Swyngedouw 2010). However, the development of new infrastructure and securing of existing supplies is known to generate positive feedbacks that increase water consumption (Kallis 2010, $\mathrm{p} 800$ ). It is not in water companies' interests to sell less of their product. A logical approach is to smooth peaks in demand when natural events such as droughts limit supplies but generally to promote the notion of security of supply at other times to ensure maximum uptake of the product, for profit (Kallis 2008 p 101). 
The need to tackle climate change through reduced consumption in addition to implementing measures to avoid socially produced water scarcity may partly explain the increasing prevalence of research focused on demand-side aspects of water management. Johnson and Handmer (2002) have identified a redistribution of risk to water customers by the water industry. In the past, the water industry has engineered out uncertainty of climate variability through increased storage and network transfer capacity but instead it is now actively shifting focus onto "demand-fix solutions" (Johnson and Handmer 2002, p347) due to reduced opportunities and high costs associated with major infrastructure projects. This has created an opportunity to allocate blame for supply failures onto customers by reframing the issue as a problem of uncontrolled demand, which has not been sufficiently curtailed by the threat of climate change. Taking an example from Australia, Sofoulis (2005) describes the situation well, explaining how water has become "in its taken-for-granted abundance a 'utility', part of the inconspicuous background of urban life, " and the customer, externalised from the commodification of the water cycle by large utility companies, is left with a "remnant of responsibility" as a 'user'; the bulk of the responsibility being maintained by water companies whose revenues will decrease if water-saving measures are successful, and the bulk of the blame being apportioned to customers who remain largely out of the control of utility companies. The constricting nature of maintained revenue combined with limited development opportunities, alongside customer confidence in supplies and unrestricted consumption, in the context of climate change, is therefore mainly dealt with by shaming the end user. This allows policy-makers, regulators, and researchers to view the situation through an industrial provision frame where customers appear to be uncontrolled/ uncontrollable while water companies are free to operate outside of this frame, virtually unimpeded, ensuring that measures to restrict customer demand such as financial penalties for high consumption households remain a last resort. This serves to re-emphasize the importance of strengthening resilience through investment in infrastructure wherever possible.

The perpetuated view of customers controlling suppliers through inexorable demands in the face of disastrous climate change, chimes with Swyngedouw's (2007) post political, post democracy where this type of socio-eco problem is an external side effect of neoliberal capitalism, where the interests of 'the people' and 'the environment' are depoliticised while "responsible scientists, environmentalists of a variety of ideological stripes and colours, together with a growing number of world leaders and politicians, keep on spreading apocalyptic and dystopian messages." (Swyngedouw 2007, p16). In this environment it is possible for the environmental social scientist to be drawn to these dystopian messages and uphold the notion that public consumption is the problem, allowing an argument for increased investment in infrastructure to persist. Nevarez (1996) charted a similar effect in his observations of a discourse of survival driven by water managers during the 1985-1991 drought in California, where continual development of infrastructure and take-up of water resources for economic growth shielded domestic customers from the realities of scarcity by enabling the provision of 'water on whim' to continue. As the drought worsened water managers were able to use emergency rationing to frame their need for more infrastructure investment for growth as a 'survival' project, forcing customers to take the blame.

This paper does not however seek to defend mass consumption of water through a critique of the evident blame culture. Instead it seeks to highlight how the UK water industry has moved away from an evenly balanced 'twin-track' approach to developing engineering solutions to water scarcity and encouraging modest behaviour change in customers, and has moved towards placing the burden of responsibility onto customers (House of Lords Science and Technology Committee 2006). This move has resulted in a substantial increase in 
environmental behaviour and market research in the area of water demand, that alongside similar work in the filed of energy use and waste minimization aims to contribute towards the development of behaviour change initiatives and takes its cue from the rhetoric of the evident blame culture. As a result the current dichotomy in demand management policy is that it is based both on the systemic and individual paradigms (Spaargaren 2011), assuming that 'the public' will eventually be forced to use water appropriately through a combination of strictly enforced regulations, prohibitive pricing, and systematically applied technological innovation but at the same time preaching to the public's moral responsibility to use less as a responsible reaction to increasing demand pressure. Spaargaren (2011) is equally critical of both paradigms; one allowing the individual to have too much choice, the other restricting the individuals' opportunities to choose to adapt positively in their own way, suggesting that failing to take time to understand the social systems and technological restraints that impact on the actions of individuals is "socially naive" (Spaargaren 2011, p2). However, assuming that from an industry perspective, the paradigms that support the blame culture are of little interest, perhaps it is more appropriate to describe modern approaches to water demand management as a product of clumsily mixing historic with rational and responsible consumer models as described by Sofoulis and Strengers (2011, cited in Sofoulis 2011), in an attempt to create integrated models that secure a sustainable future for both water companies and their customers.

\section{The Water Customer as Consumer}

It is an inescapable fact that ever increasing demand for water resources cannot be sustained. Through the rhetoric of sustainability, the protection of the environment, which may be degraded through over abstraction, is considered equally important to the provision of sanitation and clean water. Whilst exposure to the risk of not achieving the fine balance between potable water provision, waste water management and ecosystem management, can be imposed on the customer though poor management by utility companies, it is also reasonable to say that customers can inadvertently expose themselves to the risk of socioeconomic drought and environmental degradation through unchecked profligate personal use of water when supplies are limited. That the water industry is not sustainable in England can therefore be blamed on both sides - customers and water managers - as both have their part to play in protecting the environment and themselves. The principles of sustainable development are predicated on improved lifestyle management, described by O'Riordan (2004, p240) as

"The management of an evolution for a more resilient humanity on a robust planet and its peoples within ecological limits that requires losers to be aided by gainers."

Developed nations stand accused of doing little to bring about sustainable resource use whilst suffering from an "imaginary helplessness in the face of rising conspicuous consumption" (Roy and Pal 2009) and this apparent condition is worthy of research. As a result, the notion that the customer has to take full responsibility for its actions and ameliorate the prospect of water shortages through behaviour change has somewhat dominated policy initiatives in recent years, leading to a succession of studies of water-related behaviour, which according to Lam (1999) is a relative latecomer to other perceived environmental behaviours such as recycling and energy conservation, and is mainly focused on minimization actions (Barr et al. 2011a) and price increases (Allon 2006). 
There are two lenses through which one can view changes to water use behaviour; 'customer' and 'user' represent two sides in the argument of motivation and personality versus perception and culture. On examining the supply of water from a purely commercial perspective, the customer is simply required to hold a very narrow, selfish view of water as a commodity provided on demand in return for payment. When the supply of water is examined from a sustainability perspective, the customer becomes a user and is anticipated to have a much broader vision of water as a priceless environmental resource to be shared equitably within and between communities. According to James (2007 p579) this dichotomy may be resolved:

"if we recognize that culture is a statistical concept, emphasizing the recurrent regularities and persistent relations exhibited by members of a group, while personality is a clinical concept for the unique, identified individual who may participate in maintaining these group regularities but never fully conforms, always utilizing these cultural patterns in his idiomatic way for the goals and purposes he individually seeks to attain."

In the case of potable water, the prevalent water customer 'culture' is constructed by water managers through proxy measurements such as quantity used, over time (peaks and troughs in demand). This serves to overlook the individual user or 'personality', who has his or her own habits and requirements, that are impossible to identify from large data sets, and operates within the overall parameters uniquely and independently. The customer is metaphorically pitched against a conglomerate of notional water user personalities developed from attitude survey responses, allowing the predominant blame culture to persist.

Arguably, environmental social scientists attend to this by focusing on one of two extreme positions; either the individual or whole populations, and presenting water behaviour either in terms of "looming masses of populations consuming water by the gigalitre, or the little bundles of attitudes, anxieties, opinions, values and preferences called 'individuals' who are randomly encountered in close-ups of the consumer markets they constitute" (Sofoulis $2005 \mathrm{p} \mathrm{446).} \mathrm{More} \mathrm{recently,} \mathrm{these} \mathrm{subjects} \mathrm{of} \mathrm{investigation} \mathrm{have} \mathrm{been} \mathrm{confused}$ further through the application of a filter - the concept of climate change - which encourages researchers to target the individual personality through perception studies that seek to gauge willingness to act (reduce water use) to tackle the prospect of potentially diminishing water supplies, which presume the subject to have an understanding of the links between climate and water availability. These perception studies are very often contrasted against assessments of actual user practices (Dessai and Sims 2010) with the results tending to reinforce the notion of there being an attitude-action gap or a mismatch between the stated intentions of the informed customer and evidence of actual practices by the user. However, it is not correct to assume that a combination of willingness to adapt to climate change through changes in behaviour and observed behaviours that do not conform to perceived watersaving actions constitutes an attitude action gap. Without having considerable knowledge of the individual's specific circumstances, strategies, and reasoning for maintaining particular practices, and individual consumption data, it is unreasonable to make sweeping judgements that the individual customer is not behaving appropriately. However, these judgements are frequently made and this has maintained the bulk of water-related social research at "the cross-roads of personal characteristics and behavioural intentions" (Hurlimann et al. 2009, $\mathrm{p} 47$ ), and in turn has led to the development of various typologies or groups of behaviours based on stated attitudinal factors such as those described by Gilg and Barr (2005). These groups have then become targets for policy-driven information campaigns, and the circular nature of this investment in understanding, labeling, informing, observing, and 
understanding continues unabated. This perpetuates the attitude-behaviour-choice paradigm and in Shove's (2010) opinion;

"In commissioning research to address the attitude-action gap, funders reproduce precisely that understanding of social change which has generated the problem in the first place; after all the gap is only mystifying if we suppose that values do (or should) translate into action." (Shove 2010, p1276).

A recent UK Department for the Environment, Food and Rural Affairs (Defra 2012b) call for further research into water-wise messaging and how these messages can be conveyed to the public to instigate behaviour change provides further evidence that in the case of water resources management, environmental social science research has reached a rather inconclusive plateau. It also serves to maintain the predominant views within the dichotomous nature of water management without challenging any aspect of the situation directly. It is here that the authors would like to reinforce the arguments made by Shove (2010) for the application of new theoretical perspectives, and Sofoulis (2011) for the inclusion of humanities, arts and social sciences in the design phase of research projects in this area. Accordingly, this paper will review environmental social science research that utilizes (with varying degrees of success) methods designed to go beyond the $\mathrm{ABC}$.

The authors have looked for environmental social science research methods that can bridge the divide between mass culture and individual personality, to find new ways to address the problem of rising demand for water. This is not the only area where policy makers are seeking to intervene to manipulate predominant public attitudes and there have been some notable successes in areas such as health, where the balance of responsibility is more evenly distributed between actors. For example, the National Treatment Agency for Substance Misuse (NTA) recognizes the importance of supporting the families of drug users, alongside providing treatment to addicts for sustained recovery from drug abuse (NTA 2010). Although the authors are not experts in this area of research it is apparent that research undertaken on behalf of the NTA is predicated on the existence of a quantifiable problem - number of known drug users seeking treatment - and combines qualitative and quantitative data obtained through various standard methods such as questionnaires, data analysis, and interviews. The difference between this area of research and that which we are concerned with in this paper is that the problem is clearly identified and quantified and the users in this case drug users, not water company customers, are identifiable once they ask for treatment for their addiction. Perhaps our dissatisfaction with water research will not be relieved until the individuals we are targeting are identified fully through accurate consumption data but as it stands, in England and Wales, $60 \%$ of households do not have water meters (Ofwat 2011). This is a legacy of state water management where households paid an annual charge for water based on the size of their property rather than the quantity they actually used. Customers can choose to have a meter installed and in some water-stressed areas programmes to fit water meters in households are ongoing but for now, how and when we reach the point of $100 \%$ metered supply is not for discussion here. However, the fact that accurate per household data is not available across the supply network is key to our argument.

\section{Individualist Approaches to Water Use}

For a considerable period of time, policy makers have been preoccupied with finding the right mechanisms to change behaviour. Particularly focusing on smoking habits, drug 
addiction, obesity, energy consumption, travel choices, and to a lesser extent water saving. The distinction between approaches to curb eating habits for personal welfare, and initiatives to promote good environmental practices like water-saving, has not been clearly defined and is currently overshadowed by interest in narrowing the gap between expressed concern for climate change and willingness to make lifestyle changes that serve to mitigate the problem. However, our point made previously about measurement and the availability of data on known problems such as the number of obese patients or passengers making specific journeys, makes it easier to identify problems and solutions. The existence of Defra's Centre of Expertise in Influencing Behaviours (CEIB) has legitimized the absorption of initiatives that attempt to identify messages, actions, and points in time where behaviour can be influenced, into the sustainability agenda. These initiatives fall within the so called 'triangle of change' which is assumed to link government, business, and civil society together via explicit changes in habits on an individual and/or collective scale (Darnton et al. 2011; CIEB 2011). Consequently, demand-side research has become intertwined with a dialogue of sustainability and the measures associated with demand-fix solutions (altered practices, habits, and consumer choices) are measured against environmental targets (CIEB 2011). This in water terms has been translated by Defra to equate to an ambition to reduce household per capita consumption from between 150 and 160 litres to 125 litres per day. Unfortunately, without a complex collaboration between water customers, water researchers, and water companies it is not possible to identify individual over-users of water and so the successful research recipe for health-related problems cannot be followed. This is presumably why water use research is lodged principally in the domain of behavioural economics, a blend of economic theory and psychology (Jackson 2005; Darnton 2008).

Some actions are more easily quantifiable and defined as pro-environmental consumer behaviour than water use, and are therefore more easily researched. Choosing alternative transport methods or purchasing fair trade goods are examples of pro-environmental consumer behaviour. Jackson (2005) suggests that the conservation of water and energy are not consumer behaviours in the strictest sense of purchasing and might be more appropriately termed 'citizen' behaviours, as price and quality are not necessarily considered during everyday water-based tasks as the determining factors for use. This alternate label of water use as citizen behaviour may have steered research efforts towards reliance on one frequently cited model, the Theory of Planned Behaviour (Ajzen 1991). In a comprehensive review of theoretical models, Jackson (2005) describes the extensive use of a variety of methods, approaches, and ways of presenting results, asserting, "it is virtually impossible to derive universal causal models that one can construct behaviour change initiatives from" and therefore it is perplexing that so much emphasis has been placed on this model. To shed some light on other models researchers might deploy, Darnton (2008) helpfully provides a complete review of theoretical models, which are used to make sense of specific behaviours, and theories of change that can track adjustments in behaviours over time and are useful in developing interventions for the future. It is here that we argue that to break away from the circular research mode they have settled into, environmental social scientists should consider moving on from theories of behaviour at an individual level that describe attitudes, values, norms, habits and beliefs that are present, to stages of change models that can be tracked over time and begin at a measurable baseline. For example, successes in personal behaviour change for health reasons have been unpicked via the Transtheoretical Model (Velicer et al. 1998), which identifies stages of change and utilizes decisional balance and temptation scales to analyse emotions, cognitions and behaviours. In this model, self-efficacy is instrumental in providing a tipping point from one behaviour to another that is perceived to positively benefit the individual (Bandura 1977). Despite its popularity in psychology and 
health, this model has generally failed to grab the attention of environmental social scientists that are interested in investigating triggers for positive environmental behaviour.

Exceptionally, Freestone and McGoldrick (2008, p445) were breaking new ground when they applied the transtheoretical model to ethical consumerism in an attempt to identify a consumer value shift towards an "environmentally proactive mindset". However, as ethical considerations of water sit more comfortably in conservation rather than consumption, water did not feature as a consumable in this particular study. Nevertheless consideration of the use of stages of change models allows some scope to debate moving customer demand from the centre of the field and instead considering water a high-value environmental product that meets all our cleansing needs, and defining a set of appropriate citizen behaviours that go with conservative use. Or alternatively, developing the concept of profligate water use as a 'bad' habit similar to that of smoking or alcohol abuse, that enables the treatment of individuals for the symptoms of excessive habitual use. It is after all just as easy to blame tobacco companies for encouraging consumers to buy cigarettes, as it is to blame addicted smokers for not having the willpower to quit, while water companies are supported in being able to continue to feed the individuals habit for deep baths and to abstain from responsibility for dripping taps. At the very least we should be asking if it is individuals that should be somehow inspired to change behaviour through exposure to environmental messaging and climate change or if success might come through altering the context in which policy makers are developing such initiatives. It is not possible to do this while environmental social scientists rely so heavily on one or two perspectives, theories, models, and policy stances. Focusing on demand by individuals without being able to distill the quantity of water supplied to individuals from the available aggregated data leads to generalization and weak observations, which are transformed by policy-makers into one-size-fits-all messages that in the main are unworkable at the household level.

There is nothing wrong with maintaining an individualist approach to environmental social science research in the context of water management providing increasing our knowledge of customer habits, values, beliefs, and motivations is paired with detailed knowledge of actual consumption. Sadly the circular activity of behaviour research in the face of climate change and the scarcity of water framed in terms of environmental disaster and consumerism has firmly split apart the union between hydrocycle and habit, which is where technology, the water industry, and policy are positioned. Medd and Shove (2007) suggest expanding the frame of consumption research to include methods that relate to infrastructure and technology as well as consumer habits and preferences. However, water companies with a remit to promote conservation to their customers re-frame water saving from a policy perspective as new behaviour that can be learned through marketing and advice, without registering the importance of understanding the differences between customers in volumetric terms, or understanding the cultural and technical factors that set baseline consumption levels. Barr et al. (2011a) point out that social marketing reduces sustainable lifestyles down to an unproblematic and discrete set of practices. In this case these practices are all prohibitions or restrictions of water flow whilst carrying out daily tasks that range from brushing one's teeth to watering the garden. Barr and Gilg (2006) attempted to identify the characteristics of the water saver with the intention of helping policy makers target initiatives for water conservation more accurately, and note the fracture between the sectoral approach to promoting environmental action and lived experiences, arguing for research to take place where practices are undertaken. Shove (2002) has outlined through her studies of laundering behaviour, that this has resulted in an emphasis on defining beliefs, values, and attitudes, and developing persuasive methods to reduce water use. Whereas Shove advocates that the bulk of research attention should be aimed at routine practices that 
are bound up - in the case of laundering - in systems within a sociotechnical system, and where consumption practices are understood as part of performing services rather than utilising resources. This analytical rather than conceptual approach supplemented with usage data would result in a clear appraisal of modern domestic water use that might possibly be used to highlight the gap between stated intention and action but could be put to much better use in defining the behavioural, technological, cultural and contextual changes that are going to be effective in tackling water resource scarcity.

The subtlety of the distinction between these two approaches and the usefulness of accurately recorded usage data remains unexplored in recent social research commissioned by Ofwat (Creative Research 2011a) which was designed to "explore high-level customer views and attitudes to climate change and its impact on the water and sewerage services" and in particular "customers' attitudes to service and price in relation to the challenge of climate change in the long term" and "customers' appetite for changing their behaviour to use water more efficiently and manage water entering the sewers, and the trade-offs they are wiling to make." The data was collected at ten extended focus group events during which participants discussed future climate scenarios that are anticipated to result in periodic drought and flood, and their impact on the water industry's infrastructure such as cracked pipes caused by waterlogging and drying of soils; the contamination of treated water by flood water; and environmental pollution from overburdened sewage works. Unsurprisingly the resulting discussion revealed participants were inclined towards the idea of 'spending to save', in other words, to pay more for water now, to ensure that water companies are able to invest in infrastructure improvements such as larger sewers and flood protection that will increase resilience against the impact of drought and flood on vulnerable and overburdened networks in the future.

It is not necessarily the topic of discussion, or the result of this research however that causes concern but the framing and the method. Participants were screened to ensure an even spread from 'climate believer' to 'climate skeptic' were included and representation from upper and lower socio-economic groups guaranteed. The presenters closely guided the discussion and stimulus materials were provided. Facilitators were briefed to introduce the idea of spending to save into the discussion should it not be raised spontaneously (Creative Research 2011b, p92). This highlights the preconceived ideas already held by the researchers and therefore their interest in guiding the actors to the response they were already looking for. The conclusions reported were framed within the assumption that future climate change will impact on water services, behaviour change is necessary, that trade-offs are inevitable, and price is a determining factor. In other words, there could only be one of two conclusions; either the majority of customers are willing to spend to save, or they are not. Whether the conclusions would have been the same if the subjects were not so obviously guided towards these answers is not clear and to a certain extent, this type of research and analysis is contributing to what Sofoulis (2005 p446) has called a "dense fog obscuring where most research should be, framed through particular histories, discourses, and conventions." Instead, under the banner of climate change we are "re-framing the notions of environmental practice" in a way that allows "socio-ecological conflict" to arise (Barr et al. 2011b). Similarly, Shove and Warde (1998) observe that the "sociology of consumption is not well equipped to deal with environmentally critical forms of inconspicuous consumption".

\section{Framing Water Use/Practices}

The framing of environmental practices or what Jackson might term citizen behaviours in the context of climate change deserves careful analysis because it leads researchers to believe 
that the profiles they develop of individuals and groups whilst working in one area of resource use are transferrable to other resources. The authors would argue that the framing should be specific to the task at hand. The Ofwat-funded research cited in section four above has much in common with deliberative research completed on behalf of the Consumer Council for Water (Opinion Leader 2006) with the aim of building "a holisitc view of consumers' awareness, attitudes and behaviours towards water and its value in their lives." Both pieces of research developed a set of "psychographic variables" (Opinion Leader 2006, p8) or a "tentative typology" (Creative Research 2011b, p 83) that are attempts to categorise observed water-saving stances and propensity to adopt certain behaviour changes. These attempts to segment participant responses and build a general typology that can be applied elsewhere in society to categorise attitudes, perceptions and behaviours are used in the same way as one might traditionally draw upon various theories to substantiate one's views on a research outcome. However, to think that one might apply the results of this research to other study groups is probably inadvisable because it ignores the "psychological plasticity of individuals" highlighted by Levy-Leboyer (1988 p780) who noted the ease with which new psychological theories and techniques could be taken up without an understanding of their initial framing or theoretical underpinnings, where they became part of the "sad story of psychological fads." (Levy-Leboyer 1988, p780). It is therefore possible that social science researchers may follow fads more willingly than breaking new ground and experimenting with new methods, and developing new theoretical stances that might come from a less restricted view of the current situation or the change of discourse that Sofoulis (2005) advocates.

The Ofwat commissioned research cited above used two frames; participants were guided through a dystopian disaster frame and the results were viewed through a behaviour frame. Owen et al. (2009) dispensed with one frame by masking the topic of their research into the public understanding of sustainable water use in the home, to ensure subjects (home diarists and focus group attendees) gave honest answers. However, their assessment of the outcome of the research was framed within a rigid set of criteria based on a constructed definition of sustainable water use that related to specific types of technological adaptation of the home and specific adjustments to practices such as brushing teeth. Dispensing with all framing, Allon (2006 p 9) set "the environment aside as the main focus of attention," to uncover the habits and expectations of water diarists recruited to the Everyday Water project. The diaries collected provided a breadth of information that included the authors' feelings and motivations, and how they used water as a part of every-day life. This type of research sheds new light on the social construction of scarcity and the decisions individuals make regarding their choice of where and how to use water, within a "world of things, technologies, and sociotechnical systems" (Allon 2006, p20), allowing the researcher to consider a philosophical and theoretical basis for future research with substantial underpinnings that is much more likely to stand the test of time than a set of typologies.

Whilst our research observations are made in the present and immediately move into the past, theories can travel forwards in time with us, and are used to make sense of new observations rather than new observations leading to new typologies. Theories can therefore go some way to explaining behaviours but methods of investigation and the perspectives from which researchers observe subjects could be a limiting factor. Jensen (2008) provides a critique of behaviour change initiatives in Denmark where lifestyle has been the general frame within which different behaviours are observed in relation to actions that are based on environmental knowledge, or are positive in that they are perceived to be less detrimental to the environment than other possible choices. Jensen highlights the problem with linking observed actions, stated awareness of environmental issues and measured consumption data, 
with the elements of various typologies or segmentation models. He argues that while consumption data can highlight differences between consumers, it cannot reveal the individual reasoning behind specific consumption choices, or the unique blend of physical, infrastructural, and fiscal constraints that are out of the control of the actor, and cultural influences upon the actor, which also have a bearing on behaviour outcomes. Jensen concludes that the persistent lifestyle frame within which such studies are made, still places the individual consumer at the centre, despite the obvious limits to effecting change from this position. This is concerning as research by Jensen $(2008$, p359) also reveals the importance placed by individuals on not being seen as part of a "greeny segment" and as a consequence their avoidance of consumption reducing technology or habits. Jensen suggests therefore that we should openly research individual actions without being preoccupied with the root of the motivations behind them, as many every-day practices are 'green' but are not motivated by knowledge of environmental issues. Indeed one should possibly ask at this juncture whether environmental practices even exist for people who are not environmentally aware and if this is important?

This recommendation opens up other opportunities that have already been explored by Krantz (2006) in her use of Hagerstrand's (1985) time-geography and Lenntorps (1998) pockets of local order (cited in Krantz 2006, pp227-241) in making the case for not restricting studies of behaviour to isolated activities but to view activities through different constraints in varying combinations. Accordingly, time-geography identifies three specific types of constraint; capability (ability to use), coupling (consumption and transactions), and steering (authority, time, space, customs, legislature, and habits). These constraints are described as determining what is "in reach" of the individual (Krantz 2006, p231-232). In the case of household routines that utilise water these are invariably habitual and carried out in a particular way in a specific place at a specific time. The allowance of these habits or rituals such as laundering creates pockets of local order, which Krantz identifies as a useful analytical tool for studying stages of change.

\section{Questioning the Methods}

The methods utilised for environmental social science research that are open to observing myriad components of resource use within and without what has come to be regarded as conventional framing of water consumption in the context of individual motivation and use, have to capture information from multiple perspectives and surely must be structured in a way that captures data from a broader baseline of activities. Medd and Shove (2007) also argue for the inclusion of methods that relate to infrastructure and technology as well as consumer habits and preferences. However there are plenty of studies that maintain the gap between water consumer and water provider and settle on consumer behaviour and preferences utilising perception studies and questionnaires, without acknowledging their failure to look beyond stated perceptions to the worlds within which the lifestyles of study are situated or the constraints these worlds apply to subjects. This leads to an inevitable shortfall of ideas and interventions and a reliance on labeling.

The gap between our choice of research methods and society's needs has been highlighted by Ansoff (1986 p21) who argued, "most research is being done from the vantage point of single disciplines, whereas the key social problems are multi-disciplinary." However, our desire to problem-solve drives us to ask customers about their perceptions of climate and willingness to alter personal water habits or pay for increased security of supply in times of scarcity such as drought, and to apply a theoretical basis to our analysis of the results and speculate on how 
future outcomes might be manipulated using various technological, financial and moral sticks and carrots. This rather one-sided activity presumes a great deal regarding the behaviour and perceptions of water managers and future technological development. The problem with this approach is that climate and behaviour are subjects of study that are gradually changing over time. We can see this by looking at climate and historical records. The world is gradually warming and consumer preferences are changing. The daily or twice daily shower has replaced the weekly bath. In the sphere of water management, weather events and precipitation are less predictable and often more extreme, and household demand for water has become inexorable. The background to the picture is constantly changing and the frame therefore doesn't always fit.

Ansoff (1986 p 28) has also argued that; "A substantial body of social science research is not applied for the simple reason that it is not intended to be applicable." In this statement he is not implying that researchers deliberately ensure that the results of their work are of no use to anyone but that in the absence of a universally specified taxonomy of social science, researchers get confused, and often start out without identifying whether they are attempting to increase general understanding, or to solve a specific problem. The authors would argue that this statement holds true for a great number of studies that attempt to contribute to understanding of water customers' habits, beliefs, perceptions, and demands upon supply. Firstly, the framing of water customers as demanding and water providers as suppliers is too rudimentary (and worthy of lengthy debate elsewhere). Secondly, it is clear that most behavioural studies relating to consumption practices are aimed at problem solving, but due to the methods used stop short of reaching their goals by adding to our perceived knowledge of the consumer/citizen without providing robust and reliable empirically grounded data we can trust to provide firm foundations for behaviour change strategies. These concerns over our methods and achievements can be found within most studies as either critiques of others working in the field (as done in this paper), or dissatisfaction with the limit of usefulness of results. As an example, Moore et al. (1994) present a longitudinal study of domestic water conservation behaviour with a caveat that self-reports from customers may not be reliable. Whereas Syme et al. (1990) highlight the importance of the 'proper' use of data after finding a method of extracting the quantity of water used by consumers outside the home on activities such as garden watering and car washing from their total household consumption, to gain a greater understanding of links between attitudes towards conservation and external water use. More confidently, Reiss and White (2008) describe customer-billing data as a sound platform from which to interpret fluctuations in use. It would seem that researchers who are prepared to acknowledge the limits of their data and methods are often less satisfied than those who believe that they have got the right method and the right data to work with. The key here could be to be less ambitious about what we can achieve in a single study and more specific about where that study fits within the frame we are using.

Launching the Traces of Water series of UK Water Industry Research funded workshops in 2005, Medd and Shove (2007) discussed the fundamental challenges to the development of the social science of domestic water consumption, including the difficulty in distinguishing between approaches to either understanding or changing consumption and their seeming interchangeability in social science. Alongside this they voiced the importance of understanding the past history of water as a commodity and getting better acquainted with personal water practice routines, before suggesting what may or may not trigger a revaluing as a resource by the customer and/or a change of habits or an investment in water-saving technology. The conflicting views of the domestic water customer as an individual who makes choices based on needs and wants, framed within affordability, or who utilises water without thought as part of a series of daily practices was assumed to 
warrant serious examination. The inclusion of researchers interested in probing the history of the commodification of water was an important step in broadening the landscape and the actors in the frame. Trentmann and Taylor (2006) analysed the historical development that has led us to the position we find ourselves in today, meanwhile Priscoli (1998) has made a very strong case for looking at our water past and in particular water conflicts, to predict likely outcomes for water use in the future. However, the package of necessary approaches to the analysis of water use that would accomplish useful results cannot be brought together without an understanding of the individual histories surrounding the communities that comprise the consumer element of our studies. The famed participant observer, William Foote Whyte (1984) described the great contribution less experienced researchers made to his Peruvian studies by not only recording details of the participants they were sent to observe but also collecting their back stories and local histories, opening up a wealth of ideas and explanations that he personally would never have thought to collect.

\section{A Grounded Theory Approach}

Over three decades ago, Bunting and Guelke (1979) described research based on intended behaviour and stated perception alone as questionable, and argued that a new emphasis on actual behaviour was important. More recently, Medd and Chappells (2008) have called for further studies that go beyond self-reported intentions. Matching observations of behaviours to theories is a legitimate activity for the environmental social scientist and it leads to substantial quantities of descriptive work that can be used retrospectively to pinpoint changes in behaviour over time and deviation from stated intentions. The problem being that the researcher remains confined within the original constraints of past research, following the same patterns, asking the same questions and possibly repeating errors. To avoid this it is advisable to add to the research repertoire so-called grounded methods that are admittedly time consuming and therefore costly but can be carried out by just one person and require no specialist equipment or complicated computer analysis, yet can yield thousands of unique observations that help to build a more comprehensive picture of the field of research; observations that are not limited to stated perceptions and behaviours but draw on visual appraisals of the subjects surroundings and activities as well as their opinions, past histories, practices, and preferences. This rich data can be utilised to build up a picture of the present that includes dialogues from all sides, not just the consumer but also the water manager and the technology developer. The observed can also become the researcher by engaging in data collection through keeping diaries, and developing their own materials that help them to explain what they are thinking, feeling and doing, and the constraints they know are present that may not be obvious to the outsider. Freestone and McGoldrick (2008) for example introduced the Zaltman Metaphor Elicitation Technique, a patented market research tool to their work and encouraged interview subjects to produce images that helped them to convey their thoughts and feelings "The advantage of such a technique is that issues emerge from the data collected by the respondents as opposed to the researchers imposing their own thoughts and structures." (Freestone and McGoldrick 2008, $\mathrm{p}$ 451) Those being researched provided their own frames in this piece of work.

An alternative method, and to our knowledge, hitherto unused in this sphere of research is Classic Grounded Theory (Glaser and Strauss 1967), which is considered by its devotees as neither a qualitative or quantitative method but "a general research methodology occupying its own distinct paradigm on the research landscape" (Holton 2010), naturally separated from other forms of research and arguably perfect for application at the intersection between 
water management, water technology, climate change, and consumer. All types of data can be utilised to develop theory including in the case of water, questionnaire results, interviews, meter readings, diaries, photographs, secondary data from previous studies and so on. This method is not to be confused with other 'grounded theory approaches' that researchers such as Sofoulis and Allon and many others have used, where a mix of methods are deployed to collect data from subjects but a theory specifically grounded in the subject area does not emerge.

According to Charmaz (2006), Grounded Theory dispels the positivist notion of passive observers and provides systematic guidelines for probing beneath the surface and "digging into the scene" (Charmaz 2006, p23). This framework allows for systematic movement back and forth from field research to analysis. The researcher uses whatever techniques are appropriate in the field to observe, memorize, code, and identify categories with specific properties. These categories and properties are explored and analysed individually and comparatively leading to the generation of new categories and properties and so on, as the researcher returns repeatedly to the field to gather more data. This is the process of theoretical sampling (Charmaz 2006, p96) through which theory is developed. Re-visiting and re-contextualising data collected requires the development of many evolving hypotheses, which are pursued simultaneously and directed by the researcher who is guided by the mantra that "all is data" (Glaser 1998). The resulting caches are both analysed and used to prompt introspection by participants and the researcher, leading to deeper analysis and further introspection, with the aim of reaching theoretical saturation and from this point, abstracting substantive theory. The emerging theory is then subjected to a process of delimiting, described by Glaser and Strauss $(1967, \mathrm{p} 111)$ as "the reduction of terminology and consequent generalizing, forced by constant comparisons" leading to what they consider to be two major requirements of theory: "parsimony of variables and formulations and scope in the applicability of the theory to a wide range of situations, while keeping a close correspondence of theory and data."

What sets Classic Grounded Theory apart from other methods is the discipline the researcher follows in not forcing their own ideas and opinions onto the data they collect. The theory must emerge from the data rather than be overlaid on the results and chopped where it hangs over the edges or manipulated to fit. Unlike the Ofwat sponsored research mentioned earlier, the researcher sets out to hear and see "what's doin" (Glaser 2011) and to build a new theory from scratch around his/her observations rather than selecting to record observations based on their fit with pre-existing theories. As a consequence, it is impossible to predict at the outset of the research what the outcome will be and therefore a frame to set the research within is not required. If the method is followed in detail and research continues until saturation of data is reached (no new observations forthcoming) the researcher will identify a problem that needs a solution and it is quite likely that an intervention can be devised to deal with the problem once it has been identified. In the case of water consumption, the problem is unlikely to fit neatly with the behaviour changes policy makers are looking for, but it may be key to unlocking other aspects of lifestyle that by association maintain higher levels of water use than can be sustained in the long term. As an example, in their Theory of Forging a Path to Abstinence, a classic grounded theory study of Heroin users seeking detoxification, McDonnell and Van Hout (2011) identified "getting clean" as their main concern or problem and note that "The path which heroin users shape towards abstinence is defined by the resources available to them. "(McDonnell and Van Hout 2011, p20). In identifying a process of steps towards abstinence that the heroin users followed they were able to show how access to and quality of resources such as knowledge, treatments, and therapeutic alliances were important in determining whether an addict would choose to self- 
manage their withdrawal from heroin unsafely, or obtain appropriate support through the process. These observations pointed towards a need for an increase in the number of local services for heroin users to avoid the normalization of self-management of the detoxification process that can have serious medical consequences.

A key difference between doing classic grounded theory and developing social research projects using a mix of standard qualitative and quantitative methods is that while the results of other types of research can all too easily be swept up into catchy interventions that are often taken up in policy realms where there is a danger that they will be misused, Classic Grounded Theories are highly portable and can be built upon through time but they are also always connected to the subject of study. To deal with Ansoff's (1986) observations that research is often done for the sake of it and not necessarily to be applied, the Classic Grounded Theorist has to move from the substantive level to the conceptual level. According to Glaser (2011) a substantive theory that is recognisable in every-day life can be elevated to formal theory. In the case of water research and behaviour change, an intervention that grows from a substantive theory is likely to be much more useful and beneficial in the short-term, and more appealing to policy makers who may fund its development. This would be preferable than to continue to fund research that perpetuates the position environmental social scientists appear to be stuck in at present. The fact that Classic Grounded Theory was developed in the 1960s and is still in use today is testament to its appeal to researchers and usefulness in identifying and solving problems. Classic Grounded Theory is mostly used in the areas of medical and corporate research but this should not mean that its methods cannot be learned by environmental social scientists and deployed in the area of resource management, particularly as it offers the researcher an opportunity to delve into 'rich' data with a great deal of depth. The authors accept that this should not be considered the sole method by which forward motion in water demand research will be triggered after such a prolonged period of stagnation but we believe it is certainly worthy of consideration, particularly as such a broad range of data which could include individual consumption data can be incorporated into the development of a grounded theory successfully.

\section{Conclusion}

In this paper, the authors have reviewed the literature on the social science of water, explored a methodological problem, and suggested that framing of consumer-citizen behaviour research in the context of water use should be reconsidered and a more holistic approach that acknowledges the dichotomous nature of water management applied. Implicit in the discussion has been a viewpoint that environmental social science research is inadvertently supporting a blame culture that serves to perpetuate policy stances with impossible and contradictory goals while the needs of industry and customers are met at the expense of natural ecosystems. In highlighting this unintentional yet damaging state of affairs where researchers continue to make observations without making any forward progress, an opportunity has arisen to open the door to a plethora of research techniques and paradigms that might be explored in order to achieve the progress so desperately required in this important area of sustainable resource management. The authors have outlined a few alternative methods and there are undoubtedly many more combinations of methods, theories, and models that can be used and a wealth of interventions that could be experimented with, in an attempt to change behaviour for positive environmental benefit, without losing sight of overall policy goals. 
A key message that this paper is designed to convey is the benefit of approaching environmental social research with an open mind, rather than using techniques such as interviews, questionnaires, and focus groups within a specific frame, or trying to fit observations into a pre-selected framing of choice (like the ABC); to accept that it is possible to shed new light in areas where research appears static, by removing the frame altogether and letting the subjects build a new picture of their own. As Denscombe (2007, p91) explains;

"An open mind is not a blank mind on a subject. It is informed about an area, even quite aware of previous theories that might apply, but does not approach the analysis of data using preordained ways of seeing things. It avoids using previous theories and concepts to make sense of the data and thus is open to discovering new factors of relevance to an explanation of that area."

The authors would also argue that specifically in the case of attempts to reduce customer demand in the privatised water sector in the UK, individualist approaches to research should include consumption data that is applicable to studies of the individual. The point of departure for the next phase of water research therefore could be argued to be not in deciding on the frame and the filters that should be applied, but who or what should be the centre of the research and which methodology should be followed. As pressure on our most precious natural resource increases, it is more important than ever to establish clearly the reasoning decisions are based upon and what is anticipated to be achieved by continuing to research behaviours from a demand-side perspective alone, without the inclusion of a great deal of quantitative and qualitative data collected in a variety of ways. This therefore is our call to environmental social scientists to grasp the opportunity to advance our understanding of the social, cultural, and technical background to consumption decisions and practices.

Acknowledgments Rebecca Pearce was supported by an Economic and Social Research Council (ESRC) CASE studentship with the Environment Agency (ES/G041040/1). Suraje Dessai was supported by the ARCC-Water project funded by the Engineering and Physical Sciences Research Council and ESRC (EP/ G061181/1). Dr. Julian Wright is thanked for useful discussions. We would also like to thank the anonymous reviewers for their most helpful and insightful comments. Any errors remain our own.

\section{References}

Ajzen I (1991) The theory of planned behaviour. Organ Behav Hum Decis Process 50:179-211

Allon F (2006) Dams, plants, pipes and flows: From big water to everyday water. Reconstruction, 6.3 Summer 2006 reconstruction.eserver.org/063/allon.shtml Accessed 24 November 2011

Ansoff IH (1986) Evidence-The pathology of applied research in social science. In: Heller F (ed) The use and abuse of social science. Sage Publications, London, Ch 1

Bakker KJ (2003) Water: An uncooperative commodity. Privatising water in England and Wales. Oxford University Press, Oxford

Bandura A (1977) Self-efficacy: towards a unifying theory of behavioural change. Psychol Rev 84(2):191215

Barr S, Gilg A (2006) Sustainable lifestyles: framing environmental action in and around the home. Geoforum 37:906-920

Barr SW, Gilg A, Shaw G (2011a) Citizens, consumers and sustainability: (re) framing environmental practice in an age of climate change. Glob Environ Chang 21(4):1224-1233

Barr SW, Gilg A, Shaw G (2011b) Helping people make better choices: exploring the behaviour change agenda for environmental sustainability. Appl Geogr 31(2):712-720

Bunting T, Guelke L (1979) Behavioural and perception geography: a critical appraisal. Ann Assoc Am Geogr 69(3):448 
Charlton MB, Arnell NW (2011) Adapting to climate change impacts on water resources in England-an assessment of draft Water Resource Management Plans. Glob Environ Chang 21:238-248

Charmaz K (2006) Constructing grounded theory: A practical guide through qualitative research. Sage Publications Ltd, London

CIEB (2011) Developing and Using the Framework for Sustainable Lifestyles. Defra http://archive.defra. gov.uk/environment/economy/documents/sustainable-life-framework.pdf Accessed 23 February 2012

Creative Research Ltd (2011a) Attitudes towards water services in a changing climate. Report of research findings, volumes 1, June 2011, Ofwat. http://www.ofwat.gov.uk/publications/commissioned/rpt_com 201106creative_climate_findings.pdf. Accessed 12 October 2011

Creative Research Ltd (2011b) Attitudes towards water services in a changing climate. Report of research findings, Appendices, Volume 2, June 2011, Ofwat. http://www.ofwat.gov.uk/publications/commissioned/rpt_com 201106 creative_climate_appendices.pdf. Accessed 12 October 2011

Darnton A (2008) GSSR Behaviour Change Knowledge Review. Reference Report: An overview of behaviour change models and their uses. Centre for Sustainable Development, University of Westminster. http://randd.defra.gov.uk/ Document.aspx?Document=HabitsRoutinesSustainableLifestylesEVO502FinalSummaryReportNov2011(2).pdf. Accessed 23 February 2012

Darnton A, Verplanken B, White P, Whitmarsh L (2011) Habits, routines and sustainable lifestyles: A summary report to the Department for Environment, Food and Rural Affairs. AD Research \& Analysis for Defra, London

Defra (2011) Water for Life. The Stationery Office, London

Defra (2012a) The UK Climate Change Risk Assessment 2012 Evidence Report. http://www.defra.gov.uk/ environment/climate/goverment Accessed: 23 March 2012

Defra (2012b) Research competition "Testing of high-level water efficiency messaging to enable analysis of what motivates water saving behaviours." http://www.defra.gov.uk/corporate/evidence/science/researchfunding/competitions/. Accessed 12 March 2012

Denscombe M (2007) The Good Research Guide, 3rd edn. Open University Press, Milton Keynes

Dessai S, Hulme M (2004) Does climate adaptation policy need probabilities? Clim Pol 4:107-128

Dessai S, Hulme M (2007) Assessing the robustness of adaptation decisions to climate change uncertainties: a case study on water resources management in the East of England. Glob Environ Chang 17:59-72

Dessai S, Sims C (2010) Public perceptions of drought and climate change in Southeast England. Environ Hazards Hum Pol Dimens 9:340-357

Environment Agency (2003) Water Framework Directive Policy Statement, June 2003. http://www.environmentagency.gov.uk/research/library/position/41231.aspx. Accessed 23 January 2012

Environment Agency (2009) Water for people and environment, water resources strategy for England and Wales. Environment Agency, Bristol

European Commission (2007) Communication from the Commission to the European Parliament and the Council: Addressing the challenge of water scarcity and droughts in the European Union \{SEC (2007) $993\}\{$ SEC(2007) 996\} http://eur-lex.europa.eu/LexUriServ/LexUriServ.do?uri=CELEX:52007DC0414: EN:NOT> Accessed 30 July 2010

Freestone OM, McGoldrick PJ (2008) Motivations of the Ethical Consumer. J Bus Eth 79:445-467

Gilg A, Barr S (2005) Behavioural attitudes towards water saving? Evidence from a study of environmental actions. Ecol Econ 57:400-414

Glaser BG (1998) Doing grounded theory: Issues and discussions. Sociology Press, California

Glaser (2011) Personal communication on the subject of initiating Grounded Theory methods during a Grounded Theory Institute seminar. Malmo, Sweden, September 2011

Glaser BG, Strauss AL (1967) The discovery of grounded theory, strategies for qualitative research. Aldine Publishing Company, Chicago

Gleick PH (1998) Water in crisis: paths to sustainable water use. Ecol Appl 8(3):571-579

Holton J (2010) The coding process and its challenges. In: Bryant A, Charmaz K (eds) The Sage handbook of grounded theory. Sage, London, Ch13

House of Lords Science and Technology Committee (2006) Water Management, 8th Report of Sessions 20052006, Vol. 1. The Stationery Office, London

Hurlimann A, Meyer P, Dolnicar S (2009) Understanding behaviour to inform water supply management in developed nations-A review of literature, conceptual model and research agenda. University of Woollongong, Research Online, Faculty of Commerce-Papers: 47-56 http:// ro.uow.edu.au

Jackson T (2005) Motivating Sustainable Consumption: a review of evidence on consumer behaviour and behavioural change. A Report to the Sustainable Development Research Network January 2005

James O (2007) Affluenza. Vermillion, London 
Jensen JO (2008) Measuring consumption in households: interpretations and strategies. Ecol Econ 68:1-2, $353-361$

Johnson C, Handmer J (2002) Water supply in England and Wales: whose responsibility is it when things go wrong? Water Policy 4:345-366

Kallis G (2008) Droughts. Annu Rev Environ Resour 33:85-118

Kallis G (2010) Co-evolution in Water Resource Development-The vicious cycle of water supply and demand in Athens, Greece. Ecol Econ 69:796-809

Krantz H (2006) Household routines - a time-space issue: a theoretical approach applied on the case of water and sanitation. Appl Geogr 26:227-241

Lam S (1999) Predicting intentions to conserve water from the theory of planned behaviour: perceived moral obligation and perceived water right. J Appl Soc Psychol 29(5):1058-1071

Levy-Leboyer C (1988) The success and failure of applying psychology. Am Psychol 43(10):770-785

McDonnell A, Van Hout C (2011) Forging a path for abstinence from heroin: a grounded theory of detoxification -seeking. Grounded Theory Rev 10(1):17-40

Medd W, Chappells H (2008) Drought and Demand in 2006: Consumers, Water Companies and Regulators. Final Report, iii Lancaster University

Medd W, Shove E, (2007) The Sociology of Water Use. UKWIR Report 07/CU/02/2, UK Water

Moore S, Murphy M, Watson R (1994) A longitudinal study of domestic water conservation behavior. Popul Environ 16(2):175-189

Nevarez L (1996) Just wait until there's a drought: mediating environmental crises for urban growth. Antipode 28:246-272

NTA (2010) NTA Business Plan, 2010-11. The National Treatment Agency for Substance Misuse, London

O'Riordan T (2004) Environmental science, sustainability, and politics. Trans Inst Br Geogr 29:234247

Ofwat (2010) Security of Supply 2006-07 Report, Ofwat http://www.ofwat.gov.uk. Accessed 24 August 2011

Ofwat (2011) Push, Pull, Nudge-How can we help customers save water, energy, and money? Ofwat.gov.uk http://www.ofwat.gov.uk/publications/focusreports/prs_inf_pushpullnudge.pdf Accessed 03 September 2012

Opinion Leader Research (2006) Using Water Wisely: a deliberative consultation. Opinion Leader Research, London

Owen L, Bramley H, Tocock J (2009) Public understanding of sustainable water use in the home: A report to the Department for Environment, Food and Rural Affairs. Synovate. Defra, London

Priscoli JD (1998) Water and civilization: using history to reframe water policy debates and to build a New ecological realism. Water Policy 1:623-636

Rance J, Wade SD, Hurford AP, Bottius E, Reynards NS (2012) Climate Change Risk Assessment for the Water Sector. UK Climate Change Risk Assessment 2012. Defra, London

Reiss PC, White MW (2008) What changes energy consumption? Prices and public pressures. RAND J Econ 39(3):636-663

Roy J, Pal S (2009) Lifestyles and climate change: link awaiting activation? Curr Opin Environ Sustain 1:192-200

Shove E (2002) Converging Conventions of Comfort, Cleanliness and Convenience. Department of Sociology, Lancaster University, Lancaster, LA1 4YN, UK. http://www.comp.lancs.ac.uk/sociology/papers/ Shove-Converging-Conventions.pdf. Accessed 11 November 2010

Shove E (2010) Beyond the ABC: climate change policy and theories of social change. Environ Plan A 42:1273-1285

Shove E, Warde A (1998) Inconspicuous consumption: the sociology of consumption and the environment. Department of Sociology, Lancaster University, Lancaster, LA1 4YN http:/www.comp.lancs.ac.uk/ sociology/papers/Shove-Warde-Inconspicuous-Consumption.pdf Accessed 11 November 2010

Sofoulis Z (2005) Big water, everyday water: a sociotechnical perspective. Contin J Media Cult Stud 19 (4):445-463

Sofoulis Z (2011) Cross-Connections: Linking Urban Water Managers with Humanities, Arts, and Social Science Researchers. Waterlines Report Series No.60, October 2011

Spaargaren G (2011) Theories of practices: agency, technology, and culture; exploring the relevance of practice theories for the governance of sustainable consumption practices in the new world-order. Glob Environ Chang 21(3):813-822

Swyngedouw E (2007) Impossible/Undesirable Sustainability and the Post-Political Condition. In: Krueger JR, Gibbs D (eds) The Sustainable Development Paradox. Guilford Press, Guildford

Swyngedouw E (2010) Privatising H2O: Turning Local Waters into Global Money. School of Geography and the Environment, Oxford University, UK http://socgeo.ruhosting.nl/colloquium/water.pdf Accessed 11 November 2010 
Syme GJ, Seligman C, Thomas JF (1990) Predicting water consumption from homeowners' attitudes. J Environ Syst 20(2):157-168

Technology Strategy Board (2012) Water Security Competition for Feasibility and Collaborative Research and Development funding. http://www.innovateuk.org/content/competition/water-security.ashx. Accessed 8 March 2012

Trentmann F, Taylor V (2006) From users to consumers: Water politics in nineteenth-century London. In: Trentmann F (ed) The making of the consumer: Knowledge, power and identity in the modern world. Berg, Oxford, pp 53-79

Turton A, Meissner R (2002) The Hydrosocial Contract and its Manifestation in Society: A South African Case Study. In: Turton A, Henwood R (eds) Hydropolitics in the Developing World: A Southern African Perspective. African Water Issues Research Unit, Centre for International Political Studies, University of Pretoria, Johannesburg: http://www.awiru.co.za/pdf/trutonanthony7.pdf Accessed 13 September 2011

Velicer WF, Prochaska JO, Fava JL, Norman GJ, Redding CA (1998) Detailed Overview of the Transtheoretical Model based on Velicer, W. F, Prochaska, J. O., Fava, J. L., Norman, G. J., \& Redding, C. A. Smoking Cessation and Stress Management: Applications of the Transtheoretical Model of Behavior Change. Homeostasis 38:216-233

Whyte WF (1984) Learning from the field: A guide from experience. Sage, London 